\title{
Identity Economics: Social Influence and Skill Development
}

\author{
Jonathan Norris*
}

\begin{abstract}
Within the economic literature, studies in identity economics, peer effects, and skill development have all suggested that social influences have an important role in determining choices. In this review, I draw on lessons learned from the identity economics literature to examine implications from the peer effects and skill development literature. I focus on the role of social identity in generating social group effects from peers and what role identity may have in shaping the development of skills from broader environments, parents and peers during childhood and adolescence.
\end{abstract}

Keywords: identity economics; skill development; peer effects; parental skill investments

\section{Introduction}

There is a growing literature on social identity in economics with important lessons for mechanisms that generate group influence and build skills during childhood and adolescence. The contribution of this survey is to first use lessons from identity economics to suggest how group influence may work, when it is likely relevant, and how it may vary. Second, I contribute by applying these lessons to the literature on skill development and suggest how social influence may affect skill development through the broader social environment, through shifting parental investments, and through the development of identities within peer groups.

Attention in the literature to the malleability of both the cognitive and the noncognitive (socio-emotional traits, personality, etc.) skills is rising. These skills are linked with long-term well-being and economic success. Moreover, the emerging research on

*Strathclyde Business School Department of Economics, 199 Cathedral Street, Glasgow G4 0QU, Scotland, United Kingdom. E-mail: jonathan.norris@strath.ac.uk 
skills finds that skills develop during childhood and adolescence and inputs to their development have a role in creating and sustaining inequality gaps. The literature on identity in economics can both support designs of skill interventions to account for social influences and suggest further research questions around group influence and skills.

Social identity theory is one approach to understanding how social groups, social categories, and ideals create important incentives for behavior. The development of these concepts began outside of economics. In psychology, Tajfel \& Turner (1979) provided a foundational contribution. In their conception, groups form around social categories. Once group membership is internalized by an individual incentives for behavior are created that can differ between the in-group and an out-group. Discrimination, in this way, can be generated as people strive to promote their group over others. Also, Tajfel \& Turner (1979) suggested that stronger internalization of group membership generates stronger group influence, meaning group influence may vary considerably across groups. More recent work in economics has shed light on the role of identity in sustaining group influence and varying the direction of influence across groups.

I draw on this research to suggest social identity has important implications for understanding mechanisms that produce group influence, motivate parental investments in their children, and for the development of skill sets. This may be especially the case for a link between peer effects and skill development. In many respects, the peer effects literature remains unclear on predicting how and when peers will influence each other under policy designs to manipulate social groups (Sacerdote, 2014).

Policy-makers and intervention designers may care about how peers in school will influence education, risky behaviors, and other choices important to future life success. Incorporating identity will likely not facilitate social engineering of group effects, but it will allow policy and intervention designers to better understand what groups matter and how choices will be influenced across different groups. Missing this information may increase the likelihood of generating null results from such programs.

Additionally, the link between skill development and achievement later in life suggests that where identity is important any interaction with mechanisms that shape skills will lead to long-term consequences. This literature highlights the role of investments into skills at crucial junctions and that parental investment decisions have lasting consequences through impacting skill trajectories. I suggest lessons from the 
social identity literature imply identity may have a role in skill formation through shifting cues in local environments, incentives for parental investments, and through peer groups, especially during adolescence. Thereby, understanding these incentives may allow programs to improve long-term well-being by focusing on the interaction of social identities and skill investments into children and adolescents.

In the following, I first review research within economics on identity and the mechanisms that may lead to the creation of identities that then incentivize differing behaviors. Next, I turn to address a set of research questions. These are: when are group effects generated and how might identity relate to the development of skills?

\section{Identity Economics}

\section{$2.1 \quad$ The Basics}

In a seminal paper, Akerlof \& Kranton (2000) draw from the broader social sciences and formalize the concept of social identity in an economic model. They model utility for an individual $i$ with a choice of action $a_{i}$ as

$$
U_{i}=U_{i}\left(a_{i}, a_{-i}, I_{i}\right),
$$

where $a_{-i}$ are actions by those around the person and $I_{i}$ represents "self-image" or social identity. The identity function is then

$$
I_{i}=I_{i}\left(a_{i}, a_{-i} ; \boldsymbol{c}_{i}, \boldsymbol{\epsilon}_{i}, \boldsymbol{p}\right) .
$$

Identity is produced by the actions one takes and the actions of others conditional on a vector $\boldsymbol{c}_{\boldsymbol{i}}$ of one's fixed social categories, a vector of individual characteristics $\boldsymbol{\epsilon}_{i}$ (which may or may not match with those of their social category), and $\boldsymbol{p}$ the prescriptions for action (ideals) assigned to the social categories. ${ }^{1}$ Actions out of line with the prescriptions diminish identity utility and also when personal characteristics do not match those of a person's assigned category. This can potentially create a tension where a person attempts to conform in their actions but is never fully accepted by the group. In this case, group formations can create negative externalities by forcing categories upon some that they cannot match with their personal characteristics. Akerlof and Kranton's (2000) approach takes the key elements of social identity as

\footnotetext{
${ }^{1}$ Vectors are denoted in bold.
} 
predetermined, leaving for later the question of how these form. However, they map the incentives described in the psychological literature into preferences and constraints for the economics literature.

Akerlof \& Kranton (2000) discuss a number of applications where identity may be relevant. These include everything from occupational choice by gender to mountaineering. Preferences for redistribution is yet another example well covered in a survey by Costa-Font \& Cowell (2014). In this survey, I direct the focus on how identity is relevant to the development of skills that go on to have a long-term impact on education, labor market success, and in general well-being.

Akerlof \& Kranton (2002) apply the identity model directly to the case of a student in a high school who chooses their effort in school after being sorted into a group based on personal characteristics. They begin with a high school containing only the classic stereotypes of nerds, jocks, and burnouts. A student is sorted into the jocks or nerds if their personal characteristics are closest to one or the other and into the burnouts if their characteristics are too far from the other groups. Each group exerts differing ideals for effort in school. Once in a group, an adolescent gains utility from a group identity benefit, that can be diminished by failing to conform to the group norm for effort or failing to fully match the ideal personal characteristic of the group. To illustrate this concretely, I present a simple model below that is quite similar to that in Akerlof \& Kranton (2002).

The action, $a_{i}$, for this example is academic effort. Two components make up the model: utility derived from future wages and that derived from self-image. Each adolescent has personal characteristics $\boldsymbol{\epsilon}_{i} \in\left\{\eta_{i}, \iota_{i}\right\}$ where $\eta_{i}$ is ability and $\iota_{i}$ is physical appearance. Also, let $k\left(a_{i}, \eta_{i}\right)=a_{i} \eta_{i}$ be the function determining skill in the labor market. ${ }^{2}$ As in Akerlof and Kranton's paper, it is assumed to be a simple interaction. Further suppose a group $j$ exists among a set of groups with groups $G_{j} \in\left\{G_{1}, \ldots, G_{m}\right\}$ where $m$ is the number of groups. A student, $i$, is matched to a group based on their category $c_{i}$ such that $c_{i} \in\left\{G_{1}, \ldots, G_{m}\right\}$. Examples of this are being a jock with ideals to not do too well or poorly in school, seeing oneself as a "nerd" who pursues academics, or finding no status and falling into a group of "burnouts" who promote complete disengagement. ${ }^{3}$

\footnotetext{
${ }^{2}$ Physical appearance could reasonably have an impact on the wage a person can demand, as well as other characteristics, but I ignore that here for ease of exposition.

${ }^{3}$ Of course, these are highly stylized. There are any number of social categories that can be considered and that may vary from culture to culture.
} 
Each group, except for burnouts, has one ideal characteristic - ability for nerds and appearance for jocks - that when not perfectly matched reduces individual utility such that $-t\left(\alpha_{j}-\epsilon_{i}\right)$. Here $t$ is the scaling factor, $\alpha_{j}$ the group's ideal realization of the characteristic(s), and $\epsilon_{i}$, the individual characteristic, is only $\eta_{i}$ for nerds and $\iota_{i}$ for jocks. For example, if the ideal characteristic for nerds is to have a high ability level, then an individual in the group who falls below the mark will have utility gained from group membership reduced by a factor of $t$. Additionally, the group forms an ideal for effort, $a\left(G_{j}\right)$, and deviations reduce social identity utility by $-1 / 2\left(a_{i}-a\left(G_{j}\right)\right)^{2}$. Finally, each member of a group gains identity utility $I_{j}$ from group membership that is then diminished if a person's characteristics do not match the ideal of their group or their effort does not conform to the group norm. ${ }^{4}$

The utility function is given by

$$
u_{i}\left(G_{j}\right)=(1-s(\omega))\left(\delta w a_{i} \eta_{i}-\frac{1}{2} a_{i}^{2}\right)+s(\omega)\left(I_{j}-t\left(\alpha_{j}-\epsilon_{i}\right)-\frac{1}{2}\left(a_{i}-a\left(G_{j}\right)\right)^{2}\right)
$$

The parameter $\omega$ is continuous over $[0,1]$ and represents the relevance of the social identity. The function $s(\omega) \in\{0,1\}$ captures the particular weighting such that $s(0)=$ $0, s(1)=1$, and $s^{\prime}(\omega)>0 . \delta$ is a standard discount factor and $\mathrm{w}$ is wages. Maximizing $u_{i}\left(G_{j}\right)$ for effort the first order condition gives us

$$
a_{i}=(1-s(\omega)) \delta w \eta_{i}+s(\omega) a\left(G_{j}\right)
$$

Effort is a function of discounted future earnings and the group ideal for effort. Moreover, the relevance of the social identity component is important. The effect on effort from an increase in relevance is straightforward and given by

$$
\frac{\partial a_{i}}{\partial \omega}=-\frac{d s}{d \omega} \delta w \eta_{i}+\frac{d s}{d \omega} e\left(G_{j}\right)
$$

Priming, as also noted by Costa-Font \& Cowell (2014), is crucial. In the case of a student choosing effort in school, when the social identity is primed-increased in relevance - not only do we expect the group norm to become more important but also a reduction in the perceived benefit from the future. Essentially, the discount rate for future returns has been deepened, while the importance of immediate returns has

\footnotetext{
${ }^{4} I_{j}$ replaces $I_{i}$ in this simple model, implying all members in a group receive the same identity payout that is then diminished based on characteristic match and conformity.
} 
been heightened. The sign on equation 3 may depend on whether the group norm is to incentivize high or low effort. A group with a high effort ideal will still incentivize strong engagement but a group such as the burnouts face a strong disincentive to academically engage. When the relevance of the group identity is high, then simply providing information on future wages is unlikely to shift behavior.

Schools often attempt to establish a school identity or "school spirit." Put differently a school may attempt to establish social categories that have ideal characteristics and that promote effort. Akerlof \& Kranton (2002) review the education literature and point out that school policy can influence the distribution of group types in the school and the characteristics accepted into group identities that promote effort. They highlight a trade-off between a singular school identity and a more inclusive school identity. The singular identity drives high effort for those who belong to it but lower overall effort for a large share of the school who do not match the characteristic(s) promoted by the school. A more inclusive school identity may not push effort as high for any one group but it reduces the number of opposing groups with low effort.

Effort, of course, is not the only action that may be influenced by social identity and be important for development during childhood and adolescence. These could be behaviors such as drinking alcohol and crime or could merely be attitudes about education and the future. In these cases, wages are replaced by individual specific utility returns from taking the action and $\delta$ becomes a parameter weighting the personal preference. A group norm, for example, may be to have positive attitudes about the future and to be patient. Increasing the relevance of the social identity, in this case, will increase patience and investments for the future.

\subsection{Evidence on Identity Influence and Priming}

The literature in economics examining identity effects with secondary data is still quite new, while also being more descriptive and suggestive than causal. Still, the current research suggests that norms and social pressure create immediate incentives for behavior. For instance, Geerling et al. (2015) find that belonging to a group with a strong commitment to an ideal increased the likelihood of refusing information to the Gestapo in Nazi Germany compared to groups with weaker beliefs. ${ }^{5}$ This is consistent with identities that hold greater weight increasing the immediate return

\footnotetext{
${ }^{5}$ Specifically, they use data from Nazi court records and analyze groupings based on political affiliations, anti-war activist, skilled labor organizations, and non-political religious groups.
} 
from following the group ideal.

Societal pressure can also impact how one sees oneself. Costa-Font \& Jofre-Bonet (2013) find that in this way body image is impacted and through it the propensity to become anorexic. Hetschko et al. (2014) find that those who are unemployed just prior to reaching retirement age experience an increase in subjective well-being upon crossing the retirement age threshold. The implication is that the unemployed suffered from failing to meet an employed ideal pre-retirement. These studies are both consistent with the presence of a norm that dictates identity utility based on how close a person can conform to it.

Educational choice is one particular example closely related to the emphasis of the above model. If we replace effort with the choice of college major in equation 1 , then a natural set of categories to consider are male/female and a natural set of traditional characteristics may be "strong" for men and "empathetic" for women. Prescribed behavior along gender lines has traditionally pointed men and women toward differing fields of study in college and toward differing careers. One example is socially oriented, care-taking, career prescriptions for women such as the nursing field. In terms of the model in 1 and with slight adjustments, it is easy to see that the decision to match or not into one's prescribed field of study is determined by the difference in wage returns, the discount rate, and the relevance of traditional gender identity.

Humlum et al. (2012), using secondary data, find evidence consistent with gender sorting into fields of study that match traditional prescriptions. They also find that a substantial wage increase is required to compensate an individual for a change from their prescribed path. Of course, identity theory also predicts that these effects likely depend on the relevance and priming of the social identity.

A number of experimental studies in economics confirm the importance of primed social identities. Benjamin et al. (2010) conducted lab experiments with Asian American and white students at Harvard to examine the effect of ethnic norms on patience and risk preferences. They also conducted experiments at Temple University and the University of Michigan but shifted the focus to black, non-immigrant students and along gender lines. Time preferences were elicited by allowing students to make choices over receiving a monetary payment immediately or a smaller amount later. Risk preferences were elicited by allowing students to choose between accepting a small monetary payout or to take a chance on a larger payout. In the treatment 
group, the specific category (Asian-American, white, African-American, and Gender) in question was primed through filling out a survey. For example, treated Asian students answered questions about the languages spoken in their home and on how many generations their family has been in the United States. Category elicitations for the black and gender norm experiments were similarly invoked.

Treated Asian-Americans responded to the prime becoming more patient, though risk aversion did not change. White students, however, when primed did not exhibit a change in either patience or risk aversion. For black non-immigrant students, priming their race lowered their discount rate and potentially increased risk aversion. ${ }^{6}$ For gender salience, they found no significant differences. Thus, norms can vary over categories and priming different categories can elicit different economic preferences.

A few field experiments, in particular, speak further on the importance of priming identity for effort or performance. Hoff \& Pandey (2006) study outcomes in performance-based games among 6th and 7th graders in India. Participants could earn rupees for solving mazes. In the treatment group, a cultural identity featurecaste standing - was announced prior to the games and in the control it was not. In the control group, they found no difference between the performance of low and high caste students. In the treatment group, with caste standing announced, performance was significantly decreased for those of a low caste.

Returning to India, Hoff \& Pandey (2014) run a similar experiment with adjustments to consider the effect of piece-rate versus tournament designs and whether the caste composition of those around a person during the experiment is important. In each round, groups were composed of six male children with three from a high caste and three from a low cast. Caste standing was either not revealed or it was publicly revealed. Finally, a segregated grouping was employed where all boys in a group were either from a high or a low caste. Rupees were earned for each mazed solved in the piece rate regime and in the tournament regime were based on performance relative to other boys in a group.

Within mixed caste groups, publicly revealing caste created a significant disadvantage for low caste boys in the piece rate regime. Moreover, in the segregated groups publicly revealing caste resulted in underperformance by both high and low caste members. This result is somewhat striking. The authors' suggest that in some settings high-status categories possibly elicit entitlement that lowers effort, suggesting

\footnotetext{
${ }^{6}$ The evidence on risk aversion was more suggestive than conclusive.
} 
yet another dimension of heterogeneity in the effect of social identity. In the tournament design, underperformance was again observed for both low and high caste types when caste was revealed; however, the authors' put off conclusions because of the possibility of strategic factors they could not address. Overall, their evidence suggests that to be "hard-working" is less fixed than malleable, responding to cues based on social identities and the social environment.

Afridi et al. (2015) follow Hoff \& Pandey (2006, 2014) with a similar study design specific to cultural identity elements of migrant adolescents around Beijing, China. The hukou system classifies individuals as urban or rural with governmental resource allocation favoring those with an urban status over rural migrants to urban areas. The classification is passed down intergenerationally with migrants from rural to urban areas maintaining their lower hukou status. Their results were largely consistent with those of Hoff \& Pandey $(2006,2014)$. Adolescents of a low status performed worse in puzzle solving games when hukou status was announced compared to control where it was not. ${ }^{7}$

In this set of studies, we see identity features may vary in representation from culture to culture, caste and hukou, nevertheless the mechanism appears to be similar. Social identity categories that contain low status, negative features contribute to underperformance when primed. The power of words that reinforce these features may then be tied to an underlying mechanism of identity priming. Once elicited norms and expectations can shift a person to put in less effort and perform below ability.

Identity priming, of course, need not always lead to poor outcomes. In some cases, it can result in greater patience and risk aversion (Benjamin et al., 2010). This raises questions around how identities form and how and when identity categories can be shifted from negative to positive incentives. It also suggests a need to better understand how they influence development over the life course.

\footnotetext{
${ }^{7}$ They did find this result to be mitigated when the students were paid by out-performing other participants in their room, a tournament style, rather than by piece rate. This may suggest that some form of competition may help counteract a negative identity feature but it is not clear yet if this is entirely the case. Overall, their findings confirm the ability of identity salience to hinder those of a low status.
} 


\subsection{Endogenous Identity}

In the identity model outlined in equation 1, the identity utility incentives that arise stem from characteristics, groups, and ideals, or norms. These are taken as exogenous; however, given the social nature of identity it is reasonable that some elements of identity are endogenous. Norms are not stagnant but evolve across generations and are often the subject of debate and political conflict.

A number of theoretical studies have explored the choosing of norms or how identities evolve out of past decisions. Examples include family transmission of values between generations, attempts to gain political power, and discriminatory actions between groups (Kranton, 2016). Many of these studies indicate that identity evolution over time can create seemingly irrational long-term behavior.

One particular example that has received attention at the theoretical level is the formation of oppositional identities. A particular example is the formation of norms in a minority group as a reaction to discrimination by a majority group (Ogbu, 1983). Norms within the minority group are selected to be opposite the majority group norms, as a response that protects utility.

A potential determining factor for norm selection in the presence of discrimination is peer pressure. In Battu et al. (2007), a non-white group faces discrimination and networks with poor labor market opportunities. Adopting white group norms, offers non-white individuals better job opportunities. Minorities face peer pressure to reject the majority group norm along with additional incentives from cultural attachments such as language, food, and religion. A tradeoff arises, lose identity utility if adopting majority group norms or lose wages. As a result, an equilibrium can arise that is consistent with being an oppositional identity. The extent of the tradeoff depends on the strength of peer pressure. Thus, peer effects may have role in amplifying the relevance of a particular group identity.

Discrimination may also influence the relevance and spread of minority group norms. Bisin et al. (2011) model two choices: an action and intensity of identity. An increase in the level of discrimination and the number of racist individuals among the majority group, acts to reduce economic returns from integration to majority group norms and to increase the relevance of the oppositional group's identity. They also show this can create greater incentives for parents to up their efforts in transmitting "traits", or identity categories to their children.

Combined these studies suggest that oppositional identity may be particularly 
important for educational effort and attainment across communities that have experienced discrimination. With an oppositional identity formed, peers within one's community exert pressure to adopt that same identity. While not able to directly testing oppositional identity, both Fryer \& Torelli (2010) and Patacchini \& Zenou (2016) find empirical patterns consistent with peer pressure, oppositional identity within minority groups, and underperformance. Fryer \& Torelli (2010) find blacks and Hispanics in the US who perform too well in school experience reduced social status among peers of their racial/ethnic background. Patacchini \& Zenou (2016) find that having a higher percentage of same race friends increases academic performance among whites but decreases performance among blacks.

Experimental evidence indicates that students tend to select effort not just on extrinsic rewards but also on intrinsic motivations (Koch et al., 2015). If intrinsic motivation is partly about what one believes to be possible for themselves, then discrimination and oppositional identities may create beliefs among members of a minority group that educational paths dominated by the majority are not for them. Subsequently, peers may then exert additional pressure to fit in with the norms of one's community. A choice over norms can be made but deviation from group norms will be costly in terms of one's social connections.

Group identities may also evolve out of early period decisions that were not specifically about selecting norms. Hanming \& Loury (2005) model a repeated game where individuals receive an uncertain endowment draw in the first period. Personal history can be signaled through identity codes in an attempt to group together with others for risk-sharing. Common identity choice facilitates risk-sharing by acting as a vehicle to transmit important information between people.

In Hanming and Loury's model, identity choice is impacted by the degree of segregation in social interaction. Sharp cultural differences lead to less interaction between groups and creates more separated identity choice. This leads in later periods to outcomes where Pareto improving options are available but the formation of segregated collective identities prevents them.

Norms may also dictate how people treat members of an out-group. One possible origin point for the maltreatment of one group to another is in-group altruism. Darity et al. (2006) model in-group and out-group altruistic behavior. When the altruism is oriented toward one's group but excludes others, the long run externalities create entrenched racial privilege in the market place. In turn, this results in the creation of 
oppositional identity among minority groups.

Much of the theory on endogenous identity points toward differing mechanisms that can result in behavior centered around one's group. Recent experimental evidence suggests that in some cases group centric behavior can be very strong. Kranton et al. (2016) study a lab experiment in a university setting and find some participants consistently behave in what they call a "groupy" manner, supporting their own group against others even to the point of destroying out-group members income at an expense to themselves.

Kranton et al. (2016) also found heterogeneity in this behavior, indicating not all individuals respond to group treatments. One set of participants responded to any group division. A second set only responded under a salient division-political affiliation. And, a third set did not change their treatment of others based on group division.

Kranton \& Sanders (2017) explores this "groupy" behavior with a larger, more representative set of participants. They find the previous results to be robust. Moreover, they find "groupy" behavior does not correlate with any of the Big-Five personality traits and "groupy" behavior in the US appears to correlate with areas that have experienced significant negative effects from deindustrialization. Just why, however, group centric behavior tends to vary is unclear.

One potential explanation lies around the strength of identity for an individual. For an identity to become influential, it may require investment. Bénabou \& Tirole (2011) dynamically model investments into a stock of identity as $A_{t+1}=A_{t}+a_{t} r_{r}$. The investment choice is $a_{t}$ at time $t$ and $r$ the return. Their leading example is where $A$ is "relational capital". A person receives some information about their personal nature (e.g. low empathy type or a high empathy type) with imperfect recall, meaning if they are unsure they use past actions as a signal thus previous actions build up influence. Subsequently, they make an investment decision. Where no, or little investment, has been made an identity stock will be relatively small.

In turn, Bénabou \& Tirole (2011) find that investments become responsive to outside actions that may threaten identity and investment value. When peers transgress norms and taboos, identity value and investment value are threatened. Incentives are then to shun the transgressors, in both cases of deviations that are actually more prosocial or deviations that are morally abhorrent. This provides a theoretical grounding as one potential mechanism that generates the conformity effects presented in Akerlof 
\& Kranton (2000, 2002).

The authors' additionally show that where identity is weak challenges to it can yield conformity but challenges to strongly held identity can yield stiff counteractions. In past models, we see that identity priming can be important. Here threats to identity stock, where identity is strong, suggest one potential mechanism whereby priming can take place. This may explain why Kranton \& Sanders (2017) found group centric behavior to correlate with areas of the US that have experienced deindustrialization.

Social upheaval may threaten identity stocks and increase the importance of identity as a source of utility. This also fits well with the implication in Bisin et al. (2011) that parents up their identity transmission efforts as the number of role-models consistent with their identity falls. If part of parents' investment in their identity stock is identity transmission to their children, then a greater number of role-models representing a different identity threatens the transmission.

More generally the groups which may matter most to an individual's decisionmaking in later periods are the groups with whom one has the most identity investment and transmission. The extent a person internalizes a group identity relates then to the extent of shared identity investment. Group effects are more likely to be generated when in the presence of these important groups, where identity is strong, and also when the group's identity is threatened.

\section{When are Group Effects Generated?}

The study of identity in economics provides some theoretical predictions on when to expect group effects and how they may vary across contexts. This potentially has important policy relevance where group influence may have a role in the persistence of inequality. A large literature in economics explores for the presence of peer effects. This literature often has a focus on childhood and adolesent peers and to understand whether there are channels through peers that can be shifted toward better outcomes. Put another way these studies often examine peer effects out of concern for development and the closing of inequality gaps. The identity literature, however, suggests that understanding the role of group influence in development requires understanding the group identities that may be relevant, what mechanisms sort people into selecting one group or the other, whether a policy initiative itself may create threats to identity stocks, and how identities may create heterogeneity in peer influence. 


\subsection{Peer Influence}

In a review of the peer effects literature, Sacerdote (2014) finds the evidence on peer effects is often mixed, especially for academic outcomes. ${ }^{8}$ However, peer effects on behavioral and social outcomes are consistently found to be quite strong, with disruptive peers in early life especially harmful. Non-linear peer effects also appear to exist across multiple studies. One example of this heterogeneity is evidence that the test scores of high ability students benefit from high ability peers but low ability students are hindered by high ability peers. Sacerdote points out, however, that consensus is lacking for how peer effects vary by context, which peers matter most and when, and what outcomes are truly impacted.

Another strand of peer research has focused on friends during adolescence. ${ }^{9}$ Consistently, this literature finds a strong link between adolescent friend behavior and own-behavior. This is true for educational performance (Lin, 2010; Calvó-Armengol et al., 2009), and it remains the case even after employing methods to handle the endogeneity of friend selection (Goldsmith-Pinkham \& Imbens, 2013; Hsieh \& Lee, 2016). This is also true for studies on friend influence and risky behaviors such as alcohol consumption, smoking, drug use, fighting, fast food consumption, and sexual behaviors (Ajilore, 2015; Fortin \& Yazbeck, 2015; Fletcher \& Ross, 2018; Lin, 2015).

Recently, a number of studies have turned attention to the long-term implications peers may have. In studies at higher-order groupings, such as the school-grade or classroom level, the results are again mixed. Bifulco et al. (2014) find evidence that short-run effects from the cohort composition of college educated mothers in high school fade out with time. Anelli \& Peri (2016) find few significant effects from high school gender cohort composition. Black et al. (2013), on the other hand, find long-term peer compositional effects on education from cohort gender composition in Norway. Turning to friends, Patachini et al. (2016) find that the long-term educational attainment of friends' from adolescence is linked with one's own long-term attainment. Moreover, they show it is the long-term friends who matter most for long-term educational effects.

\footnotetext{
${ }^{8}$ Identification of peer effects can be difficult because of simultaneity and peer selection. A number of quality surveys exist discussing the challenges and techniques often applied. See Advani \& Malde (2018); Blume et al. (2015); Epple \& Romano (2011); Sacerdote (2014) for more.

${ }^{9}$ The primary data set for these studies has been The National Longitudinal Study of Adolescent to Adult Health (Add Health). Begun in 1995-1996 with a nationally representative sample of US high schools, this data includes a rich set of outcomes along with friend nominations within school.
} 


\subsection{Identity and Peer Influence}

Neither the studies at higher-order peer grouping levels or at the friend level directly test for an identity mechanism, but they suggest group effects appear empirically, that they appear stronger with groupings that are more relevant, and that they may vary at some grouping levels. Identity economics suggests a mechanism of social conformity effects that can help understand these results and shed light on future programs and policies that may attempt to harness peer influence.

The simple model in in equation 1 and its corresponding first order condition in equation 2 provides a social norm mechanism whereby utility is lost when not conforming to the peer norms. In the model, the peer group norm is given by $e\left(G_{j}\right)$. Empirically it might be proxied by the average behavior in the peer group or chosen on additional criteria such as a weighting for the popularity of an individual in a social network.

Additionally, identity utility falls as a person's characteristics are further away from a group ideal. Inability to match a group ideal may incentivize sorting into subgroups, such as the example of the "burnouts", and in turn lower effort. This is at least one mechanism that could generate the non-linear peer effects often observed. When paired with high ability peers, low ability peers may lose too much identity utility from failing to match the ideal and thus in turn choose new ideals and put in lower effort.

This would explain why a very relevant grouping based on friendships will return consistent results, because presumably there is matching that then allows strong conformity effects. The identity literature highlights how the degree of a social identity effect is tied to its relevance. Relevance requires internalization of ideals and, as suggested by Bénabou \& Tirole (2011), possibly investment before identity influence takes hold.

Moreover, theory and experimental evidence shows that priming matters. Peer effects will likely vary depending on how important norms are within the group or how attuned members of the group are to the norms. If more relevant groupings exhibit greater attention to, or dependence on, norms, then we would expect to see consistently strong conformity effects within those groups. Even in higher-order groupings where identities are being primed we would expect to see more salient peer group effects.

Theoretically, this priming may occur where identities come under threat, for 
example, from conflict, stress, or family environments. This in turn can lead to sharper group divides and more between group conflict. Thus, we may expect a fair degree of heterogeneity in the influence of groups.

\subsection{Heterogeneity in Group Effects}

From the peer effects literature, it appears not all peer groupings generate the same effects. Conformity has a stronger influence in more relevant groups and heterogeneity in choice of behavior exists across groups. A better understanding of these mechanisms will be important for efforts aiming to support positive development during childhood and adolescence where social influence may have a role. I now discuss evidence around heterogeneity in the influence of social groups.

An important recent point, is that choices and group selection can be related and lead to differing outcomes. Advani \& Reich (2015) model populations composed of heterogeneous groups that can develop into cooperative or uncooperative social structures. A leading example is that of interaction between immigrant minorities and local nationals. In their model, individuals are in one of these two groups but make decisions on both activities and who to interact with from either group. They model activities as those that begin with a cultural preference and those that do not (e.g. non-cultural, such playing a sport). Benefits from link formation are increasing as the number of shared activities rises, while link formation is also costly. A tradeoff exists such that maintaining cultural practices has benefits but doing so lowers crossgroup interaction.

In equilibrium, a society can form into assimilation, segregation, or multiculturalism. ${ }^{10}$ Key to the multicultural outcome are non-cultural activities that can be shared across groups and improve the benefits of interaction. Advani \& Reich (2015) find that the population share of the minority group shifts the equilibrium once past certain thresholds. As the share rises, the benefits of maintaining cultural practices becomes large enough to support either segregation or multiculturalism. The threshold itself is dependent on cultural distance between groups, the importance of culture in daily life, and the cost of link formation. In observational data, they find evidence from immigrant groups in the US that is highly consistent with their predictions and suggests that interactions across groups and resulting practices can exhibit extensive

\footnotetext{
${ }^{10}$ Here this means cultural specific actions are maintained but cross-group interaction exists around non-cultural activities.
} 
heterogeneity.

Factors that contribute to higher costs of changing activities or of forming links lowers the threshold. These factors contribute to either a segregated equilibrium or, if non-cultural activities can be coordinated, a multicultural equilibrium. Strongly held identity may increase the importance of cultural practices or raise the cost of forming links with an out-group. Benefits from links are larger as activities are shared. As ingroup members form outside links, those linking together around a cultural practice made strong by a social identity may see a threat to their own, cultural benefits. Pressure for within group conformity may grow and make cross-group links more costly.

Still a shared non-cultural activity can deflect divisiveness and promote multiculturalism, but where identity expands cultural distance, finding these activities may become difficult. Advandi and Reich find that even activities that are ex ante noncultural can become cultural in equilibrium, possibly as a way to further distinguish one group from another. Identity may have a role here, if it raises the propensity for groups to translate originally non-cultural activities into cultural ones.

A related study by Goyal et al. (2018) examines a model and experiment among university students where agents are either exogenously sorted into groups or can endogenously choose. Preferences are defined over a set of binary actions and choices on those actions can be either conforming to a majority group or diverse. Under an exogenous network structure they find conformity to majority in both their model and experiment. When agents can choose links, however, links are biased toward those who share similar preferences and diversity in action emerges. The ability to choose peer links creates groupings around preferences where within these sub-groups the preferred action can be coordinated.

Their study, in combination with identity, suggests some further questions. Their analysis does not allow for choice of continuous actions. Coordination into a group of like-minded agents allows diversity in actions, but potentially correlation of behavior within groups is simply due to selection. A follow on question is whether the social group conformity effect from the identity model still exists post-linking decisions. If so, then with endogenous link selection, we might find both increased diversity and increased intensity.

This also leaves another question. Bénabou \& Tirole (2011), discussed earlier, find that threats to identity can generate stiff counteractions where identity is strong. If the 
appearance of diversity and segregation also combines with stronger between group identities, then there may both a greater prevalence of threats to identity that prime attention to ideals and a higher chance of conflict. In fact, Goyal et al. (2018) show that conformity to the majority maximizes aggregate welfare. Thus, where diversity emerges there will be a tension between diversity and overall welfare, which may set the stage for both increased identity relevance and conflict.

There is some support for the idea that group identity increases the intensity of peer effects. Gioia (2017) elicits risk behavior by having participants choose to collect boxes that are each worth a monetary value but with one "bomb" box that destroys all earnings. Treated groups were constructed by matching participants together based on stated preferences over a set of paintings. An additional, chat group was formed similar to the painting group but prior to receiving information on peer choices each group communicated to determine who the artists of the paintings were. ${ }^{11}$ The control group was not matched together, and information on peers' choices was given before play in all but the control group.

Gioia found that peer influence reduced risk taking. Moreover, the chat group experienced much stronger peer effects as the participants felt their group was more helpful and felt more attached to the group. The added chat effect was not captured by the average, the painting and chat groups showed no difference in outcomes. Rather, it was heterogeneous to an individual's experience in the group, suggesting the peer effects were greater for those who felt more closely connected to their group. Somewhat relatedly, Chen \& Chen (2011) find that matching people with in-group members in a multiple-equilibria, minimum effort communication game can raise their effort level to a higher equilibrium level. Thus, different peer groups may have different effects that vary based on the relevance of group identity.

Heterogeneity in group effects based on identity also applies to the direction of effects between members of one's own group and those of an out-group. In an experimental design, Chen \& Li (2009) find that participants at the University of Michigan treated in-group members with greater charity when their payoffs were higher and less envy when lower. Additionally, participants exhibited greater tolerance for bad behavior from in-group than out-group members.

Klor \& Shayo (2010) experimentally examine whether preferences over redistribution are influenced by group belonging among undergraduate participants at The

\footnotetext{
${ }^{11}$ As incentive to communicate, correct answers about the artist earned additional money.
} 
Hebrew University of Jerusalem. In the group treatment, participants were sorted into groups based on having a field of study in the social sciences or the humanities and were informed of their groupings. In the control, they were sorted into groups but not informed of the groupings. Participants then faced different draws of their own and their group's wealth and made subsequent decisions over redistribution schemes that impacted how much money they could actually earn. Klor and Shayo find that their participants voted for positive redistribution when their group was poor. When the individual was poor but their group rich, they voted for lower levels of redistribution.

Goette et al. (2012) finds additional heterogeneity evidence in that the type of group can vary group effects. They study differences between a minimal group treatment - assigned to a group based on sharing the same last digit of one's social security number - and a randomly assigned "real" group - officer candidate platoons in Swiss military training who had spent significant time together. They find that superficial groupings lead to increased altruism for the in-group, while the intensive, "real", groupings punished poor behavior among in-group members-for example, defection in the prisoners dilemma-more strongly. This stronger punishment was especially the case for defections against a fellow in-group member. Thus, context of the group type matters for the direction of influence.

In keeping with the idea that context may matter for group identity effects, Kato \& Shu (2016) study the role of group identity on quality of work in the presence of workplace production incentives meant to foster competition. They use data from a textile firm in China. Workers earn more for fewer defects in a piece-rate scheme and a relative performance scheme - wage incentives tied to a worker's quality of work relative to other workers in their department - and work individually, not in teams.

Kato and Shu investigate how workers respond to the incentive schemes based on the presence of coworkers who share or do not share a particular Hukou status. ${ }^{12}$ They find that an in-group member's ability level had no effect on a person's quality of work. Out-group member's ability level, however, had a strongly positive effect. They suggest altruism for in-group members may weaken incentive schemes meant to create competition and improve quality of work, whereas out-group competition may enhance these incentives. This is again suggestive that the direction on the influence from group identity will vary with context.

Together, these findings suggest that heterogeneity can be relative to the circum-

\footnotetext{
${ }^{12}$ This is the same as was defined in section 2.2.
} 
stances of the broader group. Also, as discussed previously, oppositional identities thrive in the presence of strong group divisions. When group identities generate heterogeneity in behavior between an in-group and out-groups, it may potentially lead to greater between group conflict. Groups generate effects but effects that are based on relevant identities and that are heterogeneous. This may predict how individuals will respond differently to policy changes and to what degree group belonging will determine social preferences.

Directly of interest to much of the peer effects literature is to understand social influence on educational outcomes, which is a way of asking how peers influence human development. The general evidence in the identity literature is that social influences indeed shift behaviors, thus if they do so at crucial periods of development, efforts to close inequality gaps will need to account for them. However, to do so will require a clear distinction around where to expect social influences to operate and how they will vary. I next turn to consider skill development and the mechanisms identity may be important to.

\section{Skill Development}

In this section, I address a growing literature around the development of skills before turning in section 5 to discuss how lessons from identity economics and the creation of group influence are relevant to understanding understanding mechanisms that produce skills. Skill development is not merely cognitive. Recently, the economics literature has devoted greater attention to noncognitive skill development. Examples studied in the literature are perseverance, impulse control, trust, self-efficacy, motivation, goal setting, and more (Heckman \& Kautz, 2014). Some of these deal with how well one can control themselves and others relate to the very attitudes one forms about activities such as work and education (Lipnevich et al., 2016). Importantly, these skills remain adaptable at different points of the life cycle and likely sensitive to social influences and identity formation.

\subsection{Skills, Outcomes, and Inputs to Development}

First, why we should care about understanding the multiplicity of skills. While test scores are linked to future success, they fail to explain variation in future life outcomes, such as labor market returns, health behaviors, criminality, and more, that 
these noncognitive, or socio-emotional, skills do (Heckman \& Mosso, 2014). In general, noncognitive skills are associated with future life success across a range of dimensions (Heckman \& Kautz, 2012). Moreover, the labor market returns to soft skills have be on the rise, as a greater share of jobs are shifting towards the trading of multiple tasks between people and thus a need for better teamwork (Deming, 2017). Finally, these skills appear to not be entirely due to genes. Rather, to an extent they are malleable, especially during childhood and adolescence, suggesting they can be important to creating or closing inequalities (Heckman \& Mosso, 2014).

Effective attempts to improve skill development trajectories requires understanding contributing mechanisms throughout the life course. Heckman \& Mosso (2014) provide an extensive review of the literature around a model of skills $(\theta)$ as dynamic, with $\theta_{t+1}=f^{(t)}\left(\theta_{t}, V_{t}, \theta_{P S, t}\right)$, where $t$ represents life cycle stage. Skills in the next stage depend on past skills $\left(\theta_{t}\right)$, investments in the last stage $\left(V_{t}\right)$, and parental skills $\left(\theta_{P S, t}\right)$.

A key point on timing in the model is that skills are highly sensitive during early life. Moreover, investments build on each other, creating dynamic complementarity between early childhood endowments and investments and later period investments. This works through a link between tomorrow's skills and today's $\left(\theta_{t}\right)$. Today's skills are also a function of past inputs to the production process and contribute to the level of tomorrow's skills.

Thus, factors that shift skill development in one period can potentially be built on or negated by exposure to later investments. This raises the potential that the evolution of social identities create or interact with mechanisms related to the skill building process. Before discussing this, I review the evidence around the production of skills.

\subsection{Skills and Parents}

In terms of identity, parents represent a portion of social influence and their skill and investments are a point of emphasis in the model of skill production. The literature suggests that parental incentives to invest appear to especially differ in disadvantaged homes. A number of reviews of the literature have found that disadvantaged children often face the most negative environments with regard to parental health behaviors, that less educated mothers give less time to activities for their children's learning enrichment, and that mothers of a socio-economic disadvantage typically un- 
derestimate the impact of investing in child development (Heckman \& Mosso, 2014; Heckman, 2008).

Moreover, the actual inputs by parents appear to matter. Todd \& Wolpin (2007) find that past and present home inputs - where home inputs are measured by activities spent with the child by the parents and educational resources provided in the homeimprove student test scores. Also, Cunha \& Heckman (2008) and Cunha et al. (2010) finds that similar parental inputs positively effect cognitive skill formation at early ages, while affecting noncognitive skills into adolescence.

Time inputs also matter. Bono et al. (2016) find that maternal time inputs to children's development during early childhood positively affects cognitive and noncognitive skills. Likewise, Boca et al. (2014) find that time investments into children by both parents are important to cognitive development but that the effects diminish as the child ages. Additionally, brain development appears to be dramatically diminished if a child experiences social and intellectual neglect early in their life (Heckman, 2008). Thus, the actual inputs by parents into child development appear to be important, not just the level of parental education or resources. However, there have been some doubts raised in the literature on the efficacy of parental involvement versus more permanent background characteristics, leaving room for further work to understand how parents influence skills at different points of the life cycle (Avvisati et al., 2011).

\subsection{Investment Productivity During Childhood and Adolescence}

It is relevant to focus on the role of social identity in mechanisms for skill production during childhood and adolescence because the evidence in the literature points to skill production being most sensitive to investment during early life (Heckman \& Mosso, 2014). Some examples in the literature on the productivity of early life investments are from studies on the Perry Preschool program and the Moving to Opportunity (MTO) experiment. The Perry program was an early life intervention (begun at age 3) aiming to build cognitive and noncognitive skills among disadvantaged children in an African-American community. Outcomes for treated and control group members were followed until age 40. Heckman et al. (2013) find treated individuals experienced significant reductions in eventual criminal activity, better health behaviors, and more positive labor market outcomes, while the strongest effects ran through improved noncognitive skills. 
Chetty et al. (2016) evaluates age at time of move effects from the MTO experiment. This experiment randomly assigned some families a voucher to move out of a low-poverty area. Moving prior to the age of 13, compared to those 13 and older, had significant, positive effects on future earnings, college attendance, college quality, and neighborhood quality. Moreover, the effect of moving to a better neighborhood diminished for every year older at the time of the move. These findings are in harmony with those of Chetty \& Hendren (2015) who study families moving over US counties. Children moving to better counties - on economic and social measures - experienced increasing improvements in future outcomes for every year of exposure.

Effective interventions appear to become more difficult as a child ages. In their review, Heckman \& Mosso (2014) particularly point out that programs specifically focused on job training for adolescents have not proved successful. There is some evidence, however, that noncognitive skills can still be influenced during adolescence. Cunha et al. (2010) estimating a structural model of skill development find noncognitive skills, but not cognitive skills, remain sensitive to investments during adolescence. Also, Jackson (2012) find some 9th-grade teachers were better at boosting noncognitive ability than others and that these abilities were important to high-school completion and college attendance.

In terms of interventions during adolescence, one successful example is the Chicago OneGoal program. This program attempted to boost college attendance among disadvantaged adolescents by working on time management, goal attainment, teamwork, and self-reflection - thus noncognitive skill. Kautz \& Zanoni (2014) take advantage of variable timing in the program rollout across schools to identify the effect of the program and find the program improved college enrollment among males and females, while reducing criminality among males.

Yet, the number of studies on the malleability of skills during adolescence and the mechanisms important for successful interventions remain small in number. A recent study by Hoeschler et al. (2018) finds further evidence that grit and personality traits develop heterogeneously during adolescence, increasing for some and decreasing for others, highlighting a need to better understand development during this period.

\section{$5 \quad$ Identity and Skills}

Now, I turn to apply lessons from identity economics to the literature on skill development. Given that investments and environments matter in the production of 
skills there are a number of ways social identity may interact with the development process. I discuss these around expectations and norms in the surrounding culture, parents' identity and their investments, and one's own social groups or peers.

\subsection{Identity, Environments, and Skills}

Expectations and norms that are set by the surrounding culture may form part of the environment that skills are sensitive to. Identity priming may be an especially important factor, where regular priming by the surrounding environment may lead to habit formation. The experimental studies by Afridi et al. (2015); Hoff \& Pandey (2006) and Hoff \& Pandey (2014) suggest that when youth within low status groups have their identity consistently primed they respond with lower effort. Over time this process may build into habits and characteristics that produce skills.

Identity status may both act directly as an input to $\theta_{t+1}$ and act to moderate the effectiveness of positive investments by inducing children to respond with lower effort. Cues in the environment that prime low-status identity then shift greater weight onto the social norm, as illustrated in equation 3. Directly, the behaviors induced may establish habits and because skills are sensitive in early life these will likely impact skills. Indirectly, this may cause a person to remove attention from investments, for example by an intervention, attempting to improve skills.

One approach to interventions then is to target cues in the environment that may prime poor behaviors and attempt to shift identities toward priming better behaviors. The importance of noncognitive skills suggests that interventions should be especially concerned with cues that may prime behavior related to low self-control and poor attitudes. However, this may be easiest to implement at earlier ages. Later in life lowstatus identities may have more fully taken hold. This also relates to productivity of interventions at early life.

Environments may also lead to intergenerational passing of skill inequalities. In section 2.3 , we see theoretically that where discrimination is present oppositional identities can be created in equilibrium. As identities form within communities, discrimination may work to create inequality gaps both directly and indirectly through inputs to skill development. Inequality gaps then become deeply rooted as these identities create strong incentives for the intergenerational passing of skills within groups. 


\subsection{Identity, Parents, and Skills}

Parental skills form part of the model for skill production and parents are likely tied to the intergenerational passing of skills. In theory, parents may desire to impart certain traits or build up stock in a particular identity and place effort into building these identities in their children (Bénabou \& Tirole, 2011; Bisin et al., 2011). Parents, then, may be induced to put in more or less effort into skill investments depending on their own identity investments. For example, if parental identity has formed around behaviors that correspond with important elements of skill, such as "to be hardworking," then their investments may translate to an ideal of self-control and patience.

Interventions on parents may change their investments as their educational norms change. The skill literature implies this will affect skills and thereby behaviors related to skills. One recent field experiment suggests that indeed parental attitudes and involvement are malleable and important. Avvisati et al. (2014) study a field experiment among Parisian middle schools that aimed to improve parental attitudes about their child's school and their ability to help their child learn. They find that parental involvement with their children increased along with the parents' attitude about the school itself. The children of treated parents experienced some improvement in test scores but, importantly, significant reductions in poor behaviors.

More work, however, is needed on the ability to shift parental investments and ideals on education and noncognitive skill building. To the extent parental choice to invest in their children interacts with their identity, intervention design will need to consider the specific identity structures in a given community, what gave rise to those identities, and how interventions can work with, not against, the parents identity. These considerations will likely be especially true where oppositional identities are present and any threats to identity may yield stiff counterreactions (Bénabou \& Tirole, 2011). Because of heterogeneity in identities across populations, interventions will need to tread carefully.

The identity literature does suggest some potential directions for interventions to work on an identity mechanism. When parents' educational norms are strong but information on the key timing of investments and type of investments is lacking, then educating parents on what works may act to prime their own-identity and increase their efforts by bringing their attention to these investments.

Alternatively, in section 3 we see evidence that group influence is more likely to act on an identity mechanism when people can match into a group that is relevant 
to them. Thus, another direction is to match parents to parental peers along salient dimensions that may be relevant but where they can be exposed to higher investing parents. A similar story may also be relevant for parent-teacher matches. Importantly, however, further research needs to establish whether threats to parental identity hinder parental investments. In the case that they do, then a first step to improve parental investments may be to identify sources of identity threats and attempt to mitigate them.

\subsection{Identity, Peers, and Skills}

A clear point from the identity economics literature is to clarify when and how groups bear influence on behavior. A clear point from the skill development literature is that skills are evolving during early life and adolescence. Thus, beyond the broader environment, or parents, one's peers may influence skill production through incentivizing behaviors that build skills or interact with other factors of production.

Particularly, this is likely of growing importance in adolescence. The psychological literature tells us that it is during this time children begin to seek some level of independence from parents and relationships outside of the home become increasingly important (Bagwell \& Schmidt, 2013). This leads to questions around the role of peer influence during sensitive periods of skill development.

In section 3.3, we saw network selection and behavior can be related and stronger group relevance, through stronger group identity, may then lead to a greater intensity of group effects. Consistent with this the peer effects literature finds peer influence during adolescence to be strong when from a highly relevant group. One hypothesis is that during childhood peer groups can be thought of as simply part of the environment that children are adaptable to, and policy can manipulate, but that during adolescence peer groups take on a social identity component based on relevant groups. At this time, the literature cannot tell us but we do know that as adolescents become sensitive to the social relations they are forming outside of the home, their noncognitive skills also remain sensitive.

This can have a long-term effect by contributing to the development of noncognitive skills. Recall that evidence of peer effects during adolescence on long-term outcomes is mixed; however, it appears that much stronger influence is generated by long-term friends (Patachini et al., 2016). A multi-period identity model, such as that in Bénabou \& Tirole (2011), would be consistent with this finding. Identity 
stock builds over time. As norms become stronger, their influence persists into the future. Moreover, as norms become stronger, they become more easily primed by potential threats leading to greater tradeoffs between identity and attempts to shift peer groups, norms, and behavior. The mechanism for long-term effects that this survey suggests is that the identity building process in peer groups works through behaviors that continue to establish noncognitive skills; however, more work is needed to better understand this.

Further, what is not clear is whether adolescent period interventions targeting behaviors that may be entangled with group identities will face counterreactions from the groups to maintain cohesion. As an example, recall that in Advani \& Reich (2015) benefits from social links increase as actions are shared across links. As social links become more important during adolescence, interventions where behaviors are poor may require greater tradeoffs. Future work will need to examine whether and how equilibriums in network choice, identity formation, and behavior can be shifted postchildhood.

Policy aimed at shifting investments into skill development through changing peer groups may be simpler to implement during early childhood when peers may form part of the environment. Long-term exposure to the transmission of social identity inside and outside the family may make it difficult to integrate into different groups with alternative identities. This may explain some of the reduction in treatment effects as age at intervention rises. During adolescence shifting skill investments through shifting peer groups may require working around developing social identities.

In the case of a high school, for example, shifting a set of students out and another in may generate very different effects from school to school, depending on the structure of groups and identities. The overall set of school peers may not negatively influence the new students, but if they cannot match into meaningful groups, then positive peer influence may not be generated either. In the worst case, attempts to engineer the social network may threaten group identities and create stronger between group divides.

These are underexplored questions in the economic literature. For adolescent interventions especially, they suggest policies aiming to improve educational outcomes may need to consider both the identity structure amongst peers in-place at a school, how these lead to heterogeneous outcomes, and involving the parents, before changing the composition of the school. 


\section{Conclusion}

In this review, I examine the literature in identity economics and then apply lessons from it to the literature on peer influence and skill development. Continued research on skill development around the role of social identity has the potential to support the design of policies and interventions that can reduce inequality gaps. Missing the information this broad set of literature provides will increase the likelihood of missing important mechanisms that contribute to long-term human development and success.

Social identity research indicates that a person's social categories and prescribed ideals for behavior can strongly influence their behavior separate from individual tastes. How social identities form then is important to the evolution of social incentives over-time. Greater investments into a shared social identity in the past generates stronger internalization of the group ideals and through this stronger group effects. To be effective, intervention and policy efforts will need to carefully consider the history and structure of social identities among target populations, especially when oppositional identities may have formed.

Skill development occurs over multiple life stages and during childhood and adolescence is sensitive to investments and environments. For example, rather than simply being born with high levels of self-control or positive attitudes these characteristics can be shaped, at least to some extent. Parental transmission of ideal traits to their children forms one potential channel whereby identity formation in children may impact skills. This may lead children to be more or less willing to invest effort that over-time builds noncognitive, socio-emotional traits such as self-control. Moreover, prevailing identities within a culture, neighborhood, etc. may motivate or demotivate parental investments into skills.

Moving into adolescence, social groups outside of the home take on new found importance potentially forming another source of influence norms and behaviors related to noncognitive skill development. Subsequently, prolonged exposure to social incentives for behavior contributes to skills that once set continue to impact a person's

decisions in the long-term. Thus, continuing to build our understanding of the social processes that shape skills will better support efforts to prevent poor skill trajectories. 


\section{References}

Advani, A. \& Malde, B. (2018). Credibly identifying social effects: Accounting for network formation and measurement error. Journal of Economic Surveys.

Advani, A. \& Reich, B. (2015). Melting pot or salad bowl: The formation of heterogeneous communities. No. W15/30. IFS Working Papers.

Afridi, F., Li, S. X., \& Ren, Y. (2015). Social identity and inequality: The impact of china's hukou system. Journal of Public Economics, 123(2), 17-29.

Ajilore, O. (2015). Identifying peer effects using spatial analysis: The role of peers on risky sexual behavior. Review of Economics of the Household, 13(3), 635-652.

Akerlof, G. \& Kranton, R. (2000). Economics and identity. The Quarterly Journal of Economics, 115(3), 715-753.

Akerlof, G. \& Kranton, R. (2002). Identity and schooling: some lessons for the economics of education. Journal of Economic Literature, 40(4).

Anelli, M. \& Peri, G. (2016). The effects of high school peers' gender on college major, college performance and income. The Economic Journal.

Avvisati, F., Besbas, B., \& Guyon, N. (2011). Parental involvement in school: A literature review. Revue déconomie poltique, 120(5), 759-778.

Avvisati, F., Gurgand, M., Guyon, N., \& Maurin, E. (2014). Getting parents involved: A field experiment in deprived schools. The Review of Economic Studies, 81(1), $57-83$.

Bagwell, C. \& Schmidt, M. (2013). Friendships in Childhood and Adolescence. Guilford Press.

Battu, H., Mwale, M., \& Zenou, Y. (2007). Oppositional identities and the labor market. Journal of Population Economics, 20(3), 643-667.

Bénabou, R. \& Tirole, J. (2011). Identity, morals, and taboos: Beliefs as assets. The Quarterly Journal of Economics, 126(2), 805-855. 
Benjamin, D. J., Choi, J. J., \& Strickland, A. J. (2010). Social identity and preferences. American Economic Review, 100(4).

Bifulco, R., Fletcher, J., Oh, S. J., \& Ross, S. (2014). Do high school peers have persistent effects on college attainment and other life outcomes? Labour Economics, $29,83-90$.

Bisin, A., Patacchini, E., Verdier, T., \& Zenou, Y. (2011). Formation and persistence of oppositional identities. European Economic Review, 55(8).

Black, S., Devereux, P., \& Salvanes, K. (2013). Under pressure? the effect of peers on outcomes of young adults. Journal of Labor Economics, 31(1), 119-153.

Blume, L. E., Brock, W. A., \& Durlauf, S. N. (2015). Linear social interactions models. Journal of Political Economy, (2), 444-496.

Boca, D. D., Flinn, C., \& Wiswall, M. (2014). Household choices and child development. The Review of Economic Studies, 81(1), 137-185.

Bono, E. D., Francesconi, M., Kelly, Y., \& Sacker, A. (2016). Early maternal time investment and early child outcomes. The Economic Journal, 126(596).

Calvó-Armengol, A., Patacchini, E., \& Zenou, Y. (2009). Peer effects and social networks in education. The Review of Economic Studies, 76(4), 1239-1267.

Chen, R. \& Chen, Y. (2011). The potential of social identity for equilibrium selection. American Economic Review, (pp. 2562-2589).

Chen, Y. \& Li, S. X. (2009). Group identity and social preferences. American Economic Review, 99(1), 431-457.

Chetty, R. \& Hendren, N. (2015). The impacts of neighborhoods on intergenerational mobility: Childhood exposure effects and county-level estimates. Harvard University and NBER.

Chetty, R., Hendren, N., \& Katz, L. F. (2016). The effects of exposure to better neighborhoods on children: New evidence from the moving to opportunity experiment. American Economic Review, 106(4), 855-902. 
Costa-Font, J. \& Cowell, F. (2014). Social identity and redistributive preferences: a survey. Journal of Economic Surveys.

Costa-Font, J. \& Jofre-Bonet, M. (2013). Anorexia, body image and peer effects: evidence from a sample of european women. Economica, 80(317), 44-64.

Cunha, F. \& Heckman, J. (2008). Formulating, identifying and estimating the technology of cognitive and noncognitive skill formation. Journal of Human Resources, $43(4), 738-782$.

Cunha, F., Heckman, J., \& Schennach, S. M. (2010). Estimating the technology of cognitive and noncognitive skill formation. Econometrica, 78(3), 883.

Darity, W. A., Mason, P. L., \& Stewart, J. B. (2006). The economics of identity: the origin and persistence of racial identity norms. Journal of Economic Behavior \& Organization, 60(3), 283-305.

Deming, D. (2017). The growing importance of social skills in the labor market. The Quarterly Journal of Economics, 132(4), 1593-1640.

Epple, D. \& Romano, R. E. (2011). Chapter 20 - peer effects in education: A survey of the theory and evidence. volume 1 of Handbook of Social Economics (pp. 1053 - 1163). North-Holland.

Fletcher, J. \& Ross, S. (2018). Estimating the effects of friends on health behaviors of adolescents. Health Economics.

Fortin, B. \& Yazbeck, M. (2015). Peer effects, fast food consumption and adolescent weight gain. Journal of Health Economics, 42(42), 125-138.

Fryer, R. G. \& Torelli, P. (2010). An empirical analysis of 'acting white'. Journal of Public Economics, 94(5), 380-396.

Geerling, W., Magee, G. B., \& Brooks, R. (2015). Cooperation, defection and resistance in nazi germany. Explorations in Economic History.

Gioia, F. (2017). Peer effects on risk behaviour: The importance of group identity. Experimental Economics, 20(1), 100-129. 
Goette, L., Huffman, D., \& Meier, S. (2012). The impact of social ties on group interactions: Evidence from minimal groups and randomly assigned real groups. American Economics Journal: Microeconomics, 4(1), 101-115.

Goldsmith-Pinkham, P. \& Imbens, G. W. (2013). Social networks and the identification of peer effects. Journal of Business \& Economic Statistics, 31(3), 253-264.

Goyal, S., Hernádez, P., Martínez-Cánvasz, G., Moisan, F., Muñoz-Herrera, M., \& Sánchez, A. (2018). Integration and diversity. Cambridge-INET Working Paper Series No:2017/08.

Hanming, F. \& Loury, G. C. (2005). "dysfunctional identities" can be rational. American Economic Review, 95(2), 104-111.

Heckman, J. (2008). Schools, skills, and synapses. Economic Inquiry, 46(3), 289-324.

Heckman, J. \& Kautz, T. (2012). Hard evidence on soft skills. Labour Economics, 19(4), 451 - 464. European Association of Labour Economists 23rd annual conference, Paphos, Cyprus, 22-24th September 2011.

Heckman, J. \& Kautz, T. (2014). Fostering and measuring skills: Interventions that improve character and cognition. In The Myth of Achievement Tests: The GED and the Role of Character in American Life (pp. 341-430). Chicago, IL: University of Chicago Press.

Heckman, J. \& Mosso, S. (2014). The economics of human development and social mobility. Annual Review of Economics, 6(1), 689-733.

Heckman, J., Pinto, R., \& Savelyev, P. (2013). Understanding the mechanisms through which an influential early childhood program boosted adult outcomes. The American Economic Review, 103(6), 2052-2086.

Hetschko, C., Knabe, A., \& Schöb, R. (2014). Changing identity: Retiring from unemployment. The Economic Journal, 124(575), 149-166.

Hoeschler, P., Balestra, S., \& Backes-Gellner, U. (2018). The development of noncognitive skills in adolescence. Economic Letters, 163, 40-45.

Hoff, K. \& Pandey, P. (2006). Discrimination, social identity, and durable inequalities. American Economic Review, 96(2), 206-211. 
Hoff, K. \& Pandey, P. (2014). Making up people - the effect of identity on performance in a modernizing society. Journal of Development Economics, 106, 118-131.

Hsieh, C.-S. \& Lee, L. (2016). A social interactions model with endogenous friendship formation and selectivity. Journal of Applied Econometrics, 31(2), 301-319.

Humlum, M. K., Kleinjans, K. J., \& Nielsen, H. S. (2012). An economic analysis of identity and career choice. Economic Inquiry, 50(1).

Jackson, C. K. (2012). Non-Cognitive Ability, Test Scores, and Teacher Quality: Evidence from 9th Grade Teachers in North Carolina. Working Paper 18624, National Bureau of Economic Research.

Kato, T. \& Shu, P. (2016). Competition and social identity in the workplace: Evidence from a chinese textile firm. Journal of Economic Behavior \& Organization, 131(Part A), $37-50$.

Kautz, T. \& Zanoni, W. (2014). Measuring and fostering non-cognitive skills in adolescence: Evidence from chicago public schools and the onegoal program. University of Chicago.

Klor, E. F. \& Shayo, M. (2010). Social identity and preferences over redistribution. Journal of Public Economics, 94(3), 269-278.

Koch, A., Nafziger, J., \& Nielsen, H. S. (2015). Behavioral economics of education. Journal of Economic Behavior \& Organization, 115, 3-17.

Kranton, R. (2016). Where do social distinctions and norms come from? American Economic Review, 106(5), 405-409.

Kranton, R., Pease, M., Sanders, S., \& Huettel, S. (2016). Groupy and non-groupy behavior: Deconstructing bias in social preferences. Working Paper, Duke University.

Kranton, R. \& Sanders, S. (2017). Groupy vs. non-groupy social preferences: Personality, region, and political party. Forthcoming in the AER Papers and Proceedings.

Lin, X. (2010). Identifying peer effects in student academic achievement by spatial autoregressive models with group unobservables. Journal of Labor Economics, 28(4), $825-860$. 
Lin, X. (2015). Utilizing spatial autoregressive models to identify peer effects among adolescents. Empirical Economics, 49(3), 929-960.

Lipnevich, A., Gjicali, K., \& Krumm, S. (2016). Understanding Attitudes in Education: New Directions for Assessment, (pp. 31-64). SensePublishers: Rotterdam.

Ogbu, J. U. (1983). Schooling the inner city. Society, 21(1), 75-79.

Patacchini, E. \& Zenou, Y. (2016). Racial identity and education in social networks. Social Networks, 44, 85-94.

Patachini, E., Rainone, E., \& Zenou, Y. (2016). Heterogenous peer effects in education. Journal of Economic Behavior \& Organization, 134, 190-227.

Sacerdote, B. (2014). Experimental and quasi-experimental analysis of peer effects: Two steps forward? Annual Review of Economics, 6(1), 253-272.

Tajfel, H. \& Turner, J. (1979). An integrative theory of intergroup conflict. The social pyschology of intergroup relations, 33(47).

Todd, P. E. \& Wolpin, K. I. (2007). The production of cognitive achievement in children: Home, school, and racial test score gaps. Journal of Human Capital, (1), $91-136$. 